\title{
Digital Service Innovation in Plant and Mechanical Engineering: Exploring Contextual Factors in the Innovation Process
}

\author{
Timo Koppe \\ Technical University of Darmstadt \\ koppe@is.tu-darmstadt.de
}

\author{
Nihal Islam \\ Technical University of Darmstadt \\ $\underline{\text { islam@is.tu-darmstadt.de }}$
}

\begin{abstract}
In recent years, the transformation from pure product businesses to data-based service innovation in various industries has intensified. This paper extends previous studies on "servitization", i.e. the transition from product manufacturer to service provider, focusing on digital service innovations. We develop an integrative model to examine the technological, organizational, and environmental context as prominent components of the initiation, adoption, and routinization of digital service innovations. Drawing on the Technology-Organization-Environment (TOE) framework, different factors are identified and then validated by conducting ten expert interviews regarding their relevance to the innovation process of digital services in the plant and mechanical engineering industry. The results strongly suggest that the general TOE framework needs to be revisited and extended to be used in this specific context. The extended TOE framework can serve as a basis for studying contextual factors in digital service innovations and guide managerial decision-making.
\end{abstract}

\section{Introduction}

The digital age is hallmarked by modern technological developments. Especially, Internet of Things (IoT) and Artificial Intelligence (AI) enable service innovations [1] as well as innovative business models around access to and use of data [2]. In the meantime, these technologies have also reached traditional industries, e.g., plant and mechanical engineering. It has been widely noted that technological innovations are a primary driver for the implementation of the industrial internet or "Industry 4.0" visions [3, 4]. To prepare for this new era, incumbent firms are modernizing their IT landscape, implementing IoT platforms [5] or data science platforms [6], and changing their organizational structures [7, 8]. In addition, new actors and startups from other industries are entering the market and are competing with the incumbents. New industry IoT platforms (e.g. Siemens' Mindsphere, GE's Predix) or e-commerce platforms (e.g. Thyssenkrupp's Steel Online, Alibaba Group) are competing between the product business and after-sales services of established industry suppliers. A corresponding shift in revenue shares towards digitized product-accompanying services is expected [9].

To fully realize the business value of digitalization in the plant and mechanical engineering industry, the innovation of digital services stands out as an important research topic $[2,10]$. Companies see new opportunities for doing business by digitizing existing processes and services. In addition, they also see new opportunities to generate new business by implementing new digital services such as object self-service [11], condition monitoring, predictive maintenance or other data-based services [12].

As far as business models are concerned, these services may be linked to products and offered as Product-Service Systems (PSS) or hybrid value bundles [13, 14]. Recent studies already indicated the value of B2B service and product innovations. Managers should leverage PSS innovations where possible [15]. In doing so, the focus also shifts from the customer perspective from the product to the utility value. The manufacturers change into the role of a service provider. The pricing strategies adapt to the ownership model and change to a usage-dependent or performance-dependent calculation [16].

Although PSS and business model innovations based on life cycle and service orientation are not a new phenomenon in the industry, they gain new relevance in research and practice. In fact, they now seem to be favored by technological advances. As a well-known example of success, Rolls Royce (a worldwide leading manufacturer of engines) has demonstrated the potential of digital service innovations as a supplier of aircraft turbines. The turbines are no longer simply sold to the customer and thus become the property of the customer. Instead, the customer pays for the performance of 
the machines in a "power-by-the-hour" business model [5, 17]. These services are enabled by digital technologies such as Big Data Analytics, Machine Learning and IoT to achieve intelligent real-time performance monitoring.

The transformation from a product business to a service provider rarely takes place in a smooth and linear manner. It is often risky and traditional businesses do not seem to achieve the expected value from their investments in services [16, 18]. Prior studies show that digital service innovations in plant and mechanical engineering are still in their infancy. There are major difficulties for companies in initiation, adoption and routinization of digital services before it can generate significant business value. Digital service innovation becomes a significant research topic whereas the role of digital technologies can have a significant influence on the success of those services [19]. Further, it is important to understand the key factors that influence digital service innovation. There is a need for research on the impact of servitization and the dynamics of technology shifts in a broader environmental context $[2,10]$. Yet, these (technological, organizational, environmental) factors were examined separately in different models. This motivated us to develop an integrated model in order to investigate the contextual factors. Against this background, we seek to investigate the following research question: What specific factors affect digital service innovations in the plant and mechanical engineering industry? To answer this question, a qualitative study was conducted, which is presented in this research work.

The paper is structured as follows: In Chapter 2, we provide an overview of the theoretical background and related work to define the field of research. In Chapter 3, we describe how the qualitative study was designed, which experts were interviewed and how the interviews were executed. Then, we will present the empirical results and integrate our findings by utilizing the TOE framework in chapter 4. Furthermore we discuss our empirical results based on theoretical insights of innovation diffusion theory (DOI) and integrate the key findings to expand the TOE framework. Finally, in chapter 5 we describe the limitations as well as the contributions to research and practice.

\section{Theoretical Background and Related Work}

\subsection{Progress of servitization in the manufacturing industry}

The plant and mechanical engineering sector is traditionally characterized by physical goods [20].
For a long time, services were seen merely as an extension of the physical offer. The term servitization can now be observed in almost all industries and was first discussed by Vandermerwe and Rada [21]. Similar terms used in research are "Product Service Systems" or "Remote Product Servicing" [21, 22]. In the $1990 \mathrm{~s}$, the trend initially received little attention in mainstream engineering and management literature. Today, servitization is attracting even more attention as the service business has increasingly become the focus of many organizations, alongside the product business. There are various motives for this: First, many manufacturers from industrial nations struggle to compete on price. The declining profitability raises questions about the sustainability of the business models [18, 23]. Besides economic motives, there are various strategic (e.g. customer lock-in, market barriers) reasons for the expansion of the service business. On the demand side, customers tend to focus on core activities and avoid investments. Furthermore, the need to own production factors decreases as resources are shared more often [24, 25].

Besides these motives, servization can be favored by technological advances. There is an increase in generated data from machines and production, increased sensor technology and actuators directly on the equipment. Networking with new access options through industrial internet technologies is leading to a growth in the potential of new and innovative services [26, 27]. Various practical publications and white papers push newly developed digital business model patterns into the manufacturing industry [11]. However, strictly speaking, “-as-a-service”-models, as we know them from cloud computing [28], have been already existing in the manufacturing literature before. For example, the concept of Performance-based Contracting (PBC). PBC means that products, plants or technical systems are no longer sold to the customer, but are provided and operated by the provider or supplier itself [20, 24, 29]. The literature on PBC also contains research and models on common characteristics with a morphological box [25], PBC-component services and a typology for the classification of PBC [24]. Lastly, there is research on how $\mathrm{PBC}$ is changing the business model of the pure manufacturing company, including the boundaries between product and services as well as implications on the provider and customer relationship. This includes core characteristics of PBC in ownership, maintenance and operational responsibility, and payment structures. Performance-based pricing models such as pay-on-availability or pay-per-unit are replacing traditional pay-per-equipment [25].

Nowadays, digital technologies provide the opportunity 
for service innovations that become more efficient, are expanded or are even made possible in the first place [5]. These include predictive maintenance and prognostics and health management (PHM). Here, IoT technologies enable the monitoring and collection of machine data [30] and algorithms analyze the health status of the machines to enable IT-based predictions about the basic maintenance and optimization of these machine components in production [31].

\subsection{TOE Framework and DOI}

In general, the TOE framework provides a useful and flexible basis for the exploration of contextual factors, as it provides a generic theory for the diffusion of technologies [32]. It has therefore been widely used across different contexts and technologies such as cloud computing adoption in hospital industry [33] or the e-business usage in the financial services sector [34]. In a nutshell, the TOE framework comprises three main elements that influence the adoption process of technological innovations: (a) Technological context outlines current technologies in use as well as new technologies that are relevant to the company. (b) Organizational context refers to descriptive measures about the organization such as scope, size and management structure. Environmental context describes the area in which a company conducts its business - its industry, its competitors and its government relations [35]. This framework is consistent with Rogers' (1995) innovation diffusion theory [36], where he stressed the technological characteristics and both the internal and external features of the organization as drivers of technology diffusion [32]. Applying this view to digital service innovations in the plant and mechanical engineering industry, the assimilation of an innovation starts with the initial awareness and evaluation of the innovation. Next, the organization needs to decide to use technologies and further resources to deploy the innovation. Lastly, the new digital service innovation must be accepted, adapted and established within the organization. As we already know from servization literature of manufacturing companies, the transition to increased servization create both value and risk. Since there is little research on service innovation focusing on new digital technologies, a general TOE framework, as described above, is used as a first conceptual starting point (see Figure 1), which will be expanded in the course of our study.

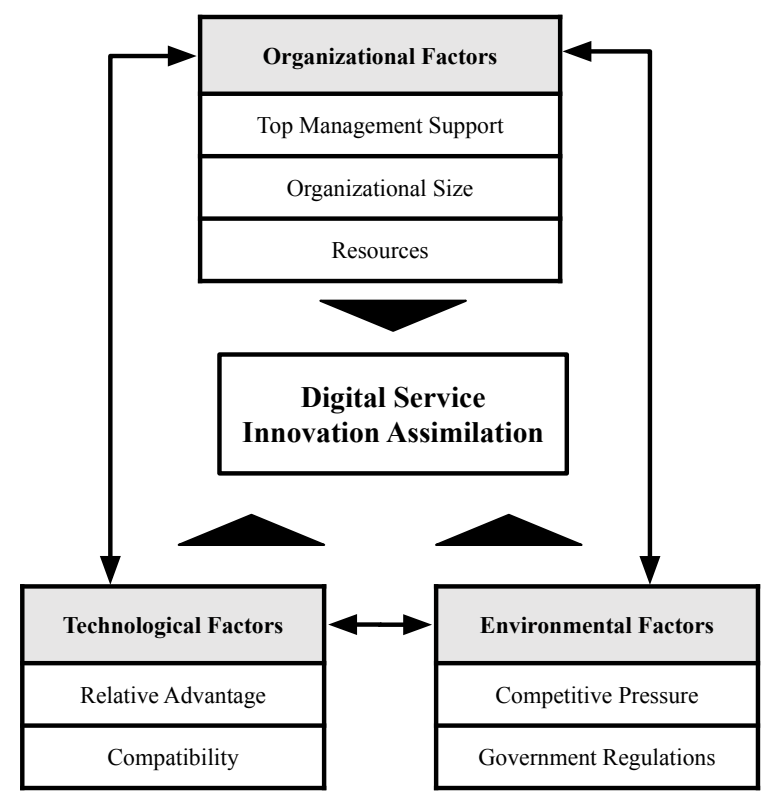

Figure 1. TOE Framework as Conceptual Base (based on $[35,36]$ )

\section{Research design, data collection and analysis process}

The goal of this research is to gain an understanding of the key factors that influence digital service innovation in a broader environmental context. In order to gain qualitative knowledge despite the rapid changes in the industry, the method of expert interviews in this field are particularly suitable, since they have quick access to current trends and changes in the industry [37]. This approach also allows us to analyze data material in areas in which only limited knowledge exists [38, 39]. In Figure 2 the interviewed experts are presented. All expert interviews were conducted in September and October 2018. Eight of the ten expert interviews were conducted by telephone and two interviews at a personal meeting. The average duration was about 45 minutes. All interviews were recorded and transcribed for easier analysis.

The research work follows the steps of content analysis based on Hsieh and Shannon, 2005 [40]: Based on the TOE framework, which serves as a conceptual framework, seven initial categories were derived from relevant literature (e.g., factors compatibility or top management support in Figure 1). These were used as a semi-structured guideline for our interviews. This guideline ensured that all interviews covered the main conceptual framework, and it allowed us to address the peculiarities of the respective firms contexts. The general questions that each interviewee was asked 
included questions about the company, the industry and existing expert understanding of "industrial internet and Industry 4.0", as well as knowledge of the company's strategic approach. Subsequently, further questions were individually selected from the following areas in each interview, depending on the course of the interview and expertise. If the companies had already started concrete initiatives with digital service innovations or had even used them, these contents were deepened in the discussion. Next, the transcribed material was paraphrased, a sequencing of the text according to semantic units. Thereby, we have used a deductive approach, as we have had theoretical assumptions in context of our research. Based on the content analysis technique and following the reducing code rules, the data material was reduced into an abstract form in order to paraphrase and generalize the data material by maintaining only the parts of substantial content, which was finally divided into categories [41] within the TOE framework. For instance, the quotation of an interviewee "We have tried to exchange with other companies (...) There is no partner who can deliver what we need off the shelf. And it is too tailor-made for that, what we have to implement here in the company." - (expert interview D1) was coded after a paraphrasing and generalizing process to factor "Strategic Collaboration and Cooperation". As required, corresponding points in the material were assigned to the categories. To achieve reliability in our analysis, multiple people (two in total) coded and analyzed the data material by using a software tool [42]. During the interviews, hints or recommendations regarding other potential interviewees were followed up. Furthermore, an attempt was made to supplement the contents of the interview partners with another interview partner who is directly upstream or downstream in the value chain. After a certain number of interviews, no further findings were added, so that after the tenth interview the search for further interview partners was interrupted as theoretical saturation was reached [43].

\section{Results}

In validating the proposed TOE framework for assimilation of innovation in digital services, we found evidence that the factors identified do not fully reflect the circumstances that companies face in initiating, integrating and establishing digital services within their organizations. Aspects that complement or contextualize the original framework (see Figure 4) are examined in more detail below. The results are presented below according to their respective contextual dimensions and associated factors.

\begin{tabular}{|c|c|c|c|c|}
\hline & Position & $\begin{array}{c}\text { Number of } \\
\text { employees } \\
\text { (2018) }\end{array}$ & $\begin{array}{c}\text { Turnover in } \\
\text { million } € \text { per } \\
\text { year }(2018)\end{array}$ & $\begin{array}{l}\text { Firm position in } \\
\text { value-chain }\end{array}$ \\
\hline A1 & $\begin{array}{l}\text { Head of Technology } \\
\text { Management }\end{array}$ & \multirow{3}{*}{$201-500$} & \multirow{3}{*}{$10-50$} & \multirow{3}{*}{$\begin{array}{l}\text { Components and } \\
\text { System Suppliers }\end{array}$} \\
\hline A2 & $\begin{array}{l}\text { Head of Product } \\
\text { Management }\end{array}$ & & & \\
\hline A3 & Sales Employee & & & \\
\hline B1 & $\begin{array}{l}\text { Head of Marketing and } \\
\text { Sales }\end{array}$ & \multirow{3}{*}{$501-1.000$} & \multirow{3}{*}{$50-250$} & \multirow{3}{*}{$\begin{array}{l}\text { Components and } \\
\text { System Suppliers }\end{array}$} \\
\hline B2 & Head of R\&D & & & \\
\hline B3 & $\begin{array}{l}\text { Program Management } \\
\text { Digital Business } \\
(\mathrm{R} \& D)\end{array}$ & & & \\
\hline C1 & CEO & $21-100$ & $10-50$ & Mechanical Engineer \\
\hline D1 & $\begin{array}{l}\text { Head of Corporate \& } \\
\text { Digital Business } \\
\text { Development }\end{array}$ & $\begin{array}{l}5.001- \\
15.000\end{array}$ & $1.000-5.000$ & $\begin{array}{l}\text { Mechanical Engineer } \\
\text { and provider of an } \\
\text { industrial platform }\end{array}$ \\
\hline E1 & $\begin{array}{l}\text { Business Unit Manager } \\
\text { Marketing \& Sales }\end{array}$ & $\begin{array}{l}100.000- \\
150.000\end{array}$ & $\begin{array}{l}10.000- \\
50.000\end{array}$ & $\begin{array}{c}\text { Supplier, solution \& } \\
\text { system provider and } \\
\text { provider of an industrial } \\
\text { platform }\end{array}$ \\
\hline F1 & $\begin{array}{l}\text { Member of the Board } \\
\text { of Management, and } \\
\text { Head of the Industry } \\
\text { Division }\end{array}$ & $\begin{array}{r}100.000 \\
-150.000\end{array}$ & $\begin{array}{l}10.000- \\
50.000\end{array}$ & $\begin{array}{c}\text { Supplier, solution \& } \\
\text { system provider and } \\
\text { provider of an industrial } \\
\text { platform }\end{array}$ \\
\hline
\end{tabular}

Figure 2. Overview of interviewed experts

\subsection{Environmental Factors}

According to the experts, the positions in the value-chain of plant and mechanical engineering are simplified: Component supplier, solution and system supplier, mechanical engineer, system integrator / provider of an industry IoT platform and the (end-)customer (see Figure 3). The (end) customer is characterized by the fact that he uses the machine or systems in his own production. All companies (A - F) indicate to be concerned with the industrial internet technologies for internal (own production and processes), as well as external purposes (products and services). In addition, two companies also provide their industrial internet platform as technical solution on the market which they originally developed for internal purposes.

Market Characteristics and Economic Situation. The plant and mechanical engineering sector is characterized by its "handicraft", specialized intermediaries and technical complexity. Expertise is tied to people who have the necessary experience in the selection of components. Long availability, warranties and the 


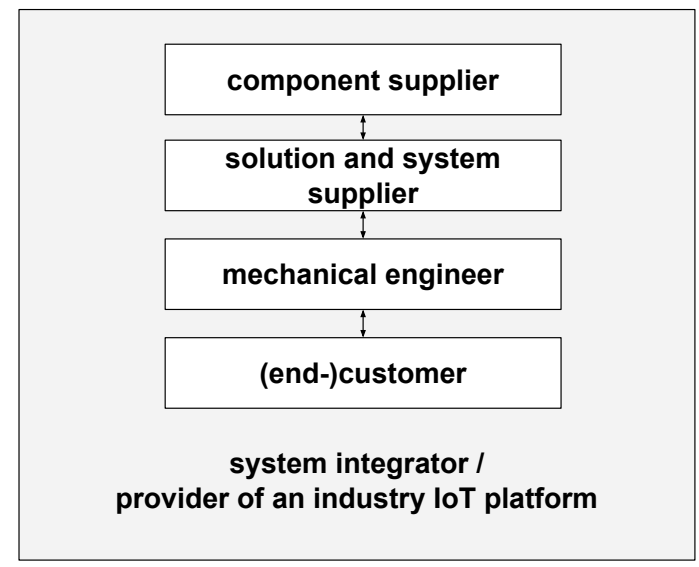

Figure 3. Relationships between the companies of interviewed experts

reputation of the manufacturer create trust and signal a promise of quality. After the sale of components and systems, suppliers and component manufacturers have little insight into the end customer's use and customer's processes, except in service and warranty cases. In addition, intermediaries have important application know-how. They know the requirements and complexity to be considered when designing components, right through to installation and integration in systems and plants. According to the experts, missing uniform standards, safety concerns and a long-lasting installed base are challenges to be mastered.

All experts report that digitalization and industrial internet have become a dominant topic. However, there is much skepticism and uncertainty about the concrete changes in the industry as a result of digitalization. Both small and large industrial companies describe the market as very immature regarding new technological standards. Actors in the market are experimenting a lot. New industrial internet technology platforms, like industrial IoT Platforms, are emerging and various concepts of operator models are tested. Some new business models are emerging, which, however, do not completely replace the old ones.

"In five years we plan to make $10 \%$ of our total turnover with the new subscription model (...) We don't want to compare the new world with the old world - the old world will still make up a large part of our turnover." - D1

Some suppliers with a large installed base in the market are using the hyped "Industry 4.0" as a sales argument and are already offering the first successful digital business models. So far, it cannot be observed that partners and dealers are dropping out of the value chain.

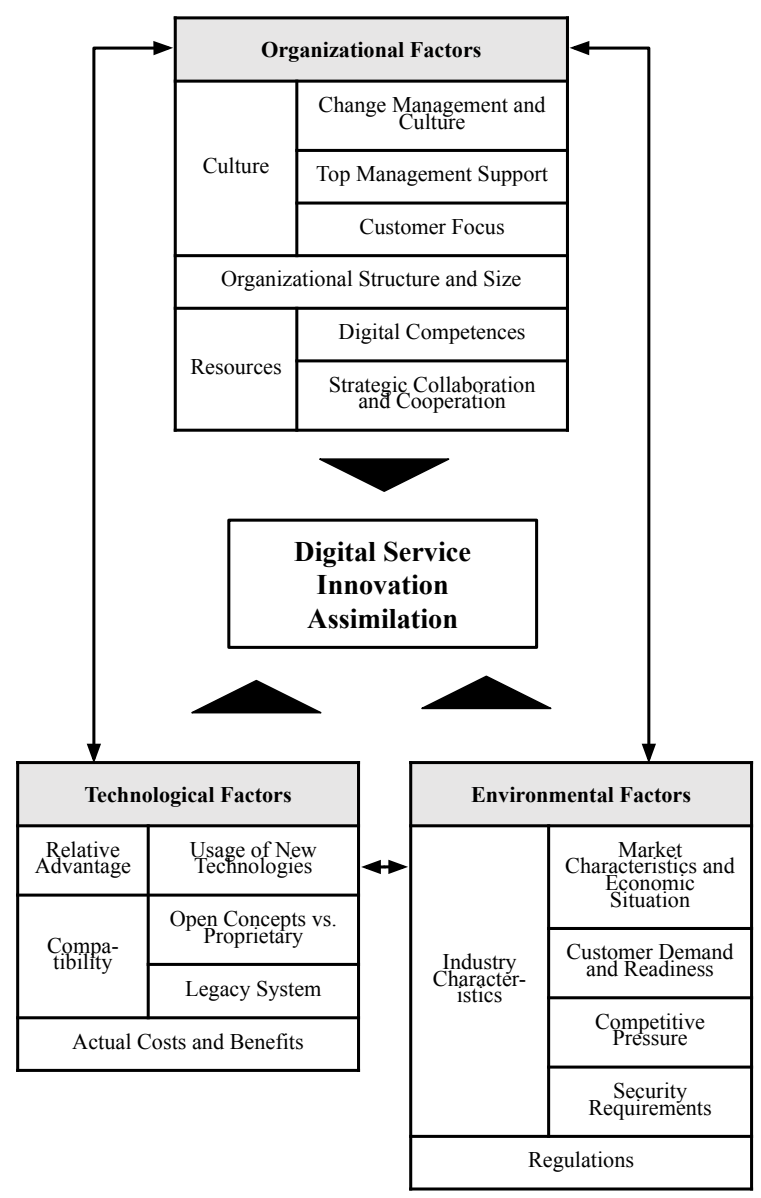

Figure 4. Extended and deepened framework for Digital Service Assimilation

It is assumed that especially the system integrator will become more important in the future and offer more services. The dealer feel secure due to their specific application knowledge in the respective industry.

Customer Demand and Readiness. All of the interviewed experts work in companies that already have been established in the industry for many years and serve international markets. Although an existing customer base with a large installed base creates advantages in many respects, the experts also reported about disadvantages in terms of the deployment of new technologies:

"Certain technology developments we simply cannot do because of market penetration, so we have to go for established solutions because our customers confront us with a minimum availability of 10 years (...) usually we have 20, 25 years. This of course also slows 
down developments." - C1

Over many years, a large number of different suppliers has led to a multitude of interfaces, different norms, and standards. Due to customer requirements for a high minimum availability, long warranties and long-lasting conventional technologies, systems and components have been used by customers for several decades. With regard to the initiation of new digital service innovations (e.g. more sensors with digital value-added functions), experts report a lack of customer feedback.

"Of course we try with all our efforts to think more in the direction of the end customer and to get in contact with them, to pick up the requirements (...) but I have the feeling that the end customers do not really know that yet." - A1

Important requirements and feedback on innovations mainly come from the end customer, who ultimately consumes the services. This is a challenge for all actors involved, especially those with no direct (end-)customer interface. Companies C- F can observe more customer requirements for new digital services on the market than companies A - B.

Concerning the customer requirements, experts say that their customers are looking for integrated services to either achieve the same output with less input, or increase output with the same input. Ultimately, the customer goal is to improve design, engineering, operation and maintenance of machines, increase productivity and performance, and reduce total cost of ownership. Further objectives are automated supply chains and the implementation of interfaces for partners and suppliers in order to have consumables even more precisely on site. However, all customers and suppliers in the machinery and plant industry are still very reticent about the opportunities and risks of digitalization.

"We see a growing need to get this data. However, we do not yet see at the moment where exactly the added value has been created." - B2

Although customers want more data and digitization, they themselves often don't know what to do with it.

"Both our customers and end-customers they are asking what can we do with all this data?" - B3

Security Requirements. Security requirements for the adoption and utilization of new digital services in customer processes are another important factor within the industry.
"Firewall and Cloud, many customers have hell of a respect for it because they are afraid that they will be hacked and that you will have to open the firewall." - B1

The availability of data derived from the use of PSS is a central prerequisite for digital service innovations. At present, the topics of data handling and ownership have not yet been clarified in industry. In addition, there is a need to embed production and process data from the customer application, especially in cases of holistic analyses and optimizations. However, this information often represents the customer's intellectual property. Therefore, the customer usually blocks access to such data, especially if it is a permanent connection in real-time transmission. First approaches (e.g. isolated data connection, industrial gateways) try to address this issue. However, there is still a lack of experience or trust in such solutions.

Competitive Pressure. So far, experts report a watchful eye on the market, technical standards and new digital business models. Some actors in the industry fear that if trends are missed, the only thing left to do is to supply mechanics and others will become the "application know-how" carriers.

"At the end of the day, I then only concentrate purely on the mechanics, because we are then unrolled on the software side, i.e. on the interface side." A2

The currently high growth figures and high demand in the industry are also confronting organizations with the decision either to build up personnel resources, expand their machine park or expand digitalization to increase efficiency.

Regulations. In particular, the experts highlighted the warranties, data protection and intellectual property protection, and product warranties as important criteria factors for digital service innovations. These factors are often still unclear in the definition of service offerings, are subject to country-specific differences and slow down innovation.

\subsection{Technological Factors}

Usage of New Technologies. The term Industry 4.0 is understood in different ways by the interviewed experts and is often circumscribed by examples. For some, the addition of a controller and specific software to the product already counts as Industry 4.0, for others, it is about the use of augmented reality in the assembly of the machine. What all the experts have in common is that Industry 4.0 deals with data acquisition over 
the entire life cycle, starting with planning, production, and use till the end-of-the life. The use of new industrial internet technologies as well as connected and integrated data footprints constitute a central element for new business models. These new opportunities concern every area and activity, from marketing, sales, $\mathrm{R} \& \mathrm{D}$, purchasing, production, customer operations to after-sales services. Especially by accessing data during the use of their products and components, manufacturers can offer their customers services such as analysis, predictive maintenance, scheduling of maintenance intervals and performance improvements

Open Concepts vs. Proprietary. New technologies, on the other hand, may be very immature and challenge manufacturers to change familiar patterns and criteria when selecting suppliers, partners and standards. In addition, manufacturers see risks in protecting their core competencies if they open up their interfaces and systems:

"Every player in the market has different ideas about business models and if you focus on an open interface (...) you will certainly reveal your own added value or core competencies." - A2

Legacy System. Experts report that customers expect the manufacturer to continue to support the older systems. One problem of services like predictive maintenance is, that their "machines, they all live much too long" (Expert B1). These challenges also mean that many manufacturers already have very different degrees of digitization maturity.

Actual Costs and Benefits. Organizations use industrial internet technologies to equip their products (from equipment parts to entire technical infrastructures) with more intelligence and functionality through software, sensors, and actuators. Subsequently, these products are often referred to as Smart Products. The experts have identified various goals, requirements, and challenges regarding digital service innovations. Six goals were identified:

- Improvement of service quality and efficiency through remote monitoring and over-the-air maintenance

- Increased process control, ease of use, product functionality and product flexibility through software components (digital add-ons) for configuration and free programmability

- Improved product development through knowledge of weak points and usage scenarios
- Increased reliability and reliability through predictive maintenance and product self-service

- Advanced asset management and energy optimization to increase operator efficiency

- Enable new business models such as "lot size 1", sensor-data-as-a-service, analytics-as-a-service, pay-per-availability and pay-per-result.

However, it is also reported that developments of industrial internet technologies are perceived as risky and costly.

\subsection{Organizational Factors}

Change Management and Culture. Since the expected transformation from industrial internet technologies is taking place in all business areas, experts see that these are still inadequately prepared and thus hinder successful implementation. Examples include sales employees who have recently been involved in IT-specific customer discussions but lack the technical know-how to do so.

As already introduced, digital business models with new revenue models affect the provider's entire product portfolio. Every corporate function as well as customer and supplier relationships change according to the experts. The transactional business model is replaced by recurring payment models. The sale will never be concluded through beneficial and needs-oriented life cycle services such as performance-based contracting.

"This is a disruptive change here in the company and a company that in the past was clearly focused on a transactional business, i.e. from all processes starting with sales to the systems behind them. (...) I have a product that I price through whatever approach and I sell the product once, customer pays, process completed. (...) Now when you get into a model (...) where we are going in the direction of recurring revenue, where we simply have a recurring business that is based on the output of the customer, it naturally changes the whole company." - D1

Departments have to control the monitoring of machines at the customer's site. The necessary infrastructure for lifelong product support must be in place and in operation. The systems are continuously further developed in the R\&D of the manufacturer through data and customer feedback and constantly improved in the production of the customer. Finally, service teams must 
guarantee reliability.

The new world is generating numerous resistances. Even if a company wants to introduce less disruptive business models, "smart products" or data-driven services, a lot of internal convincing and coordination work is necessary. Not only the employees, functions, or departments in the company have to adapt, but also the application software or IT systems in use must be designed to map out the necessary service provision. All experts agree that current structures and cooperation within the traditional manufacturing organization have not yet been designed for this.

"Oh collaboration, thats also a very difficult point. In many many companies I see that between sales and innovation it is very hard. Like two sides of War. So when Digitalization comes up where you kind of have to work together, and this creates a lot of conflicts." - B3

Top Management Support. Companies that use new technologies to drive digital services innovation must adapt organizationally. New staff positions for digitization are introduced and top management is being involved. However, some experts report on a lack of management capacity for everything together.

Customer Focus. In addition, customer requirements in the development of PSS and digital service innovations are often unclear or even unknown. These may be based on individual assumptions and prejudices, without knowing the actual willingness to pay and without obtaining the customer's requirements. However this is highly valued by the experts and should be considered as critical KPI in the initiation and evaluation of the innovation:

"One difficult thing with digitalization and changing your business models and everything: You cannot say - Okay that's my ROI [...] in exact numbers. So I have tried other ways. So I'm looking for example into KPIs of customer engagement." - B3

Organizational Structure and Size. Larger companies that have already successfully implemented digital initiatives have built cross-functional competence centers. They are equipped with decision-making and instruction powers. Furthermore, the departments need to be well integrated with the existing organization through representatives in each area. The goal is to create synergies between the digital projects, to promote digital understanding within the company and to prepare the company to offer new business models in the future:
"(...) first started as a project (...) then said, we have to place it somewhere in the line-organization, as a central and independent unit in a division of the board (...) with interdisciplinary staff (...) and equipped with decision-making powers. (...) You have to imagine it like this, we are organized into product divisions. (...) then I say I am building a service that covers all products. That means that I am automatically involved in the discussion of all products and product areas. I have to change support and reporting structures, I have to adapt the IT system, which is geared towards transactional business (...). This means that my team will then create many small task forces, you have to imagine very agile speedboats that will then eat their way into the organization and tackle the corresponding topic areas as soon as they have been identified." - D1

Digital Competences. Emerging industrial internet technologies such as data mining, analytics, AI or the Industrial IoT require specialist knowledge. Sales and marketing of the manufacturer must be trained to better communicate the value generated and benefits gained through digital services.

"Suddenly, Sales is no longer talking to the engineers, but to the IT department, and we realize that our employees are not at all prepared for this." - B1

Furthermore, there is a lack of competence in the further areas of business models, e.g. with regard to new types of contracts, sales processes and tax aspects.

Strategic Collaboration and Cooperation. According to the experts, manufacturing companies must continue to encourage the establishment of new ways of working and collaboration. Individual hurdles in the disclosure of information and specialist knowledge within the company must be overcome. More proactive corporate communication and top management support is needed. In most areas, there are still too many gaps in knowledge and too little interest in digitization and IT. "Hardly any company in the industry has the complete know-how in this interdisciplinary field" (Expert F1). Therefore, it is necessary to work in partnership with customers and suppliers, even if some of them are competitors.

"An AI expert company alone lacks the domain knowledge. When you automate something it is important to understand the process, the equipment and what it means to increase productivity." - F1 


\section{Conclusion, Limitation, and Outlook}

Over the last 40 years, global competition from developing countries has put organizations in industrialized countries under great pressure. Not least for this reason, the expansion of the service business is increasingly moving into the focus of industry. In the meantime, this industry, as well as other industries, has been affected by the ongoing digitalization. As we know from other industries, such as the information and communications technology industry with cloud computing, new providers with digital business models are threatening existing business models or are even bringing them to a standstill. Still, there are major difficulties for established organizations in initiating, introducing and routinizing digital services before they can generate significant business value. In this area, the innovation of digital services is an important research topic.

Our qualitative study extends previous studies on servitization, i.e. the transition from product manufacturer to service provider, focusing on digital service innovations. Moreover, the study illustrates challenges of industrial organization in their transition to a service provider. The results of the study were presented as an extended TOE framework with consideration of the DOI theory which can serve as a basis for further research and guide managerial decision-making. Altogether, a framework for the assimilation of digital service innovation is proposed. This enables companies to carry out a structured analysis of their status quo and identifying areas of improvements in the assimilation of digital service innovations.

As any study, our qualitative research underlies several limitations. However, at the same time, these limitations provide interesting avenues for further research. Due to the interpretive nature of our research, the results we described represent the sense-making process of the researchers. Subjective personal judgments cannot be ruled out completely, even though we took great care to reflect the subjects opinions as correctly as possible. Despite the limitations, our study makes three contributions: Firstly, by using the TOE framework with consideration of the DOI theory, we have illustrated insights what factors are relevant in the context of digital service innovation assimilation. Therefore, analysis was carried out considering all players in the value chain. Secondly, we have emphasized that the transformation process to a service-oriented provider and organizational change will be critical to success, so further research and practice is needed in this field of research. Against this background, we have outlined an approach for future work and provided our identified factors as a basis for the research discussion. Thirdly, for practitioners, we have shown the potential of digital service innovation in frame of transformation process and are offering some guidance to the further development of transformation process of industrial companies in plant and mechanical engineering into a service-oriented provider.

\section{References}

[1] M. Barrett, E. Davidson, J. Prabhu, and S. L. Vargo, "Service innovation in the digital age: key contributions and future directions," MIS quarterly, vol. 39, no. 1, pp. $135-154,2015$.

[2] D. Bilgeri, F. Wortmann, and E. Fleisch, "How Digital Transformation Affects Large Manufacturing Companies' Organization," International Conference on Information Systems (ICIS), pp. 91-99, 2017.

[3] P. Gölzer, P. Cato, and M. Amberg, "Data processing requirements of industry 4.0 - use cases for big data applications," in ECIS, 2015.

[4] H. Lasi, P. Fettke, H.-G. Kemper, T. Feld, and M. Hoffmann, "Industry 4.0," Business \& information systems engineering, vol. 6, no. 4, pp. 239-242, 2014.

[5] J. P. Shim, M. Avital, A. R. Dennis, M. Rossi, C. Sørensen, and A. French, "The transformative effect of the internet of things on business and society," Communications of the Association for Information Systems, vol. 44, no. 1, pp. 129-140, 2019.

[6] S. Schiller, M. Goul, L. S. Iyer, R. Sharda, D. Schrader, and D. Asamoah, "Build your dream (Not just big) analytics program," Communications of the Association for Information Systems, vol. 37, no. 1, pp. 811-826, 2015.

[7] I. Haffke, B. Kalgovas, and A. Benlian, "Options for transforming the it function using bimodal it.," MIS Quarterly Executive, vol. 16, no. 2, pp. 101 - 120, 2017.

[8] D. Bilgeri, E. Fleisch, and F. Wortmann, "How the iot affects multibusiness industrial companies: Iot organizational archetypes," in International Conference on Information Systems (ICIS), 2018.

[9] I. M. Sebastian, K. G. Moloney, J. W. Ross, N. O. Fonstad, C. Beath, and M. Mocker, "How big old companies navigate digital transformation," MIS Quarterly Executive, vol. 16, no. 3, pp. 197-213, 2017.

[10] B. Tim, Z. B. Ali, B. O. F., S. V. Guang, B. James, and R. Keith, "Servitization: revisiting the state-of-the-art and research priorities," International Journal of Operations \& Production Management, vol. 37, pp. 256-278, jan 2017.

[11] E. Fleisch, M. Weinberger, and F. Wortmann, "Business models and the internet of things," in Interoperability and Open-Source Solutions for the Internet of Things, pp. 6-10, Springer, 2015.

[12] M. Bulger, G. Taylor, and R. Schroeder, "Data-driven business models: challenges and opportunities of big data," Oxford Internet Institute. Research Councils UK: NEMODE, New Economic Models in the Digital Economy, 2014. 
[13] D. Veit, E. Clemons, A. Benlian, P. Buxmann, T. Hess, D. Kundisch, J. M. Leimeister, P. Loos, and M. Spann, "Business models," Business \& Information Systems Engineering, vol. 6, no. 1, pp. 45-53, 2014.

[14] D. Jaspert and J. Dohms, "Reorganization of Companies through Digital Servitization: A Systematic Review," in AMCIS 2020 PROCEEDINGS, vol. 23, 2020.

[15] T. Dotzel and V. Shankar, "The Relative Effects of Business-to-Business (vs. Business-to-Consumer) Service Innovations on Firm Value and Firm Risk: An Empirical Analysis," Journal of Marketing, vol. 83, no. 5, pp. 133-152, 2019.

[16] H. Gebauer, E. Fleisch, and T. Friedli, "Overcoming the service paradox in manufacturing companies," European management journal, vol. 23, no. 1, pp. 14-26, 2005.

[17] K. Selviaridis and F. Wynstra, "Performance-based contracting: a literature review and future research directions," International Journal of Production Research, vol. 53, no. 12, pp. 3505-3540, 2015.

[18] A. Neely, "Exploring the financial consequences of the servitization of manufacturing," Operations management research, vol. 1, no. 2, pp. 103-118, 2008.

[19] T. Dotzel, V. Shankar, and L. L. Berry, "Service innovativeness and firm value," Journal of Marketing Research, vol. 50, no. 2, pp. 259-276, 2013.

[20] C. Buse, J. Freiling, and S. Weissenfels, "Turning product business into service business: Performance contracting as a challenge of sme customer/supplier networks, paper presents at the 17," in th Annual IMP Conference in Oslo/Norway (2001, Citeseer, 2001.

[21] S. Vandermerwe and J. Rada, "Servitization of business: adding value by adding services," European management journal, vol. 6, no. 4, pp. 314-324, 1988.

[22] M. G. Sharma and K. Singh, "Servitization, coopetition, and sustainability: An operations perspective in aviation industry," Vikalpa, vol. 42, no. 3, pp. 145-152, 2017.

[23] D. Sainsbury, "The race to the top: A review of governments science and innovation policies. hm treasury, london,” Eğifimde Geleneksel Anlayışa Yeni Bir $S$ (I) TEM, vol. 67, 2007.

[24] C. Belz and M. Wuensche, "Classification of performance contracting solutions: a managerial typology," paper presented at the 2nd International Conference on Business Market Management, 25-27 March, Delft, 2007.

[25] A. Gustafsson, S. Brax, L. Witell, P. Hypko, M. Tilebein, and R. Gleich, "Clarifying the concept of performance-based contracting in manufacturing industries," Journal of Service Management, 2010.

[26] J. Huxtable and D. Schaefer, "On servitization of the manufacturing industry in the uk," Procedia CIRP, vol. 52, no. 1, pp. 46-51, 2016.

[27] M. M. Herterich, T. Buehnen, F. Uebernickel, and W. Brenner, "A taxonomy of industrial service systems enabled by digital product innovation," in 2016 49th Hawaii International Conference on System Sciences (HICSS), pp. 1236-1245, IEEE, 2016.

[28] S. Stuckenberg, E. Fielt, and T. Loser, "The impact of software-as-a-service on business models of leading software vendors: experiences from three exploratory case studies," in Proceedings of the 15th Pacific Asia Conference on Information Systems (PACIS 2011), Queensland University of Technology, 2011.
[29] S.-H. Kim, M. A. Cohen, and S. Netessine, "Performance contracting in after-sales service supply chains," Management science, vol. 53, no. 12, pp. 1843-1858, 2007.

[30] F. Wortmann and K. Flüchter, "Internet of things," Business \& Information Systems Engineering, vol. 57, no. 3, pp. 221-224, 2015.

[31] J. Lee, E. Lapira, B. Bagheri, and H.-a. Kao, "Recent advances and trends in predictive manufacturing systems in big data environment," Manufacturing letters, vol. 1, no. 1, pp. 38-41, 2013.

[32] K. Zhu and K. L. Kraemer, "Post-adoption variations in usage and value of e-business by organizations: cross-country evidence from the retail industry," Information systems research, vol. 16, no. 1, pp. 61-84, 2005.

[33] J.-W. Lian, D. C. Yen, and Y.-T. Wang, "An exploratory study to understand the critical factors affecting the decision to adopt cloud computing in taiwan hospital," International Journal of Information Management, vol. 34, no. 1, pp. 28-36, 2014.

[34] K. Zhu, K. L. Kraemer, and J. Dedrick, "Information technology payoff in e-business environments: An international perspective on value creation of e-business in the financial services industry," Journal of management information systems, vol. 21 , no. 1 , pp. 17-54, 2004.

[35] R. Depietro, E. Wiarda, and M. Fleischer, "The context for change: Organization, technology and environment," The processes of technological innovation, vol. 199, no. 0, pp. 151-175, 1990.

[36] E. M. Rogers, "Diffusion of innovations: modifications of a model for telecommunications," in Die diffusion von innovationen in der telekommunikation, pp. 25-38, Springer, 1995.

[37] A. Bogner, B. Littig, and W. Menz, Interviewing experts. Springer, 2009.

[38] K. A. Neuendorf, "Defining content analysis," Content analysis guidebook. Thousand Oaks, CA: Sage, 2002.

[39] R. K. Yin, "Case study research: Design and methods. sage publications," Thousand oaks, 2009.

[40] H.-F. Hsieh and S. E. Shannon, "Three approaches to qualitative content analysis," Qualitative health research, vol. 15, no. 9, pp. 1277-1288, 2005.

[41] J. Corbin and A. Strauss, Basics of qualitative research: Techniques and procedures for developing grounded theory. Sage publications, 2014.

[42] L. Richards, Handling qualitative data: A practical guide. Sage, 2014.

[43] U. Flick, "Triangulation in qualitative research," $A$ companion to qualitative research, vol. 3, pp. 178-183, 2004. 